\title{
Varia
}

Folia phoniat. 1976;28:126-128

\section{In memoriam Professor Dr. med. Miloslav Seeman}

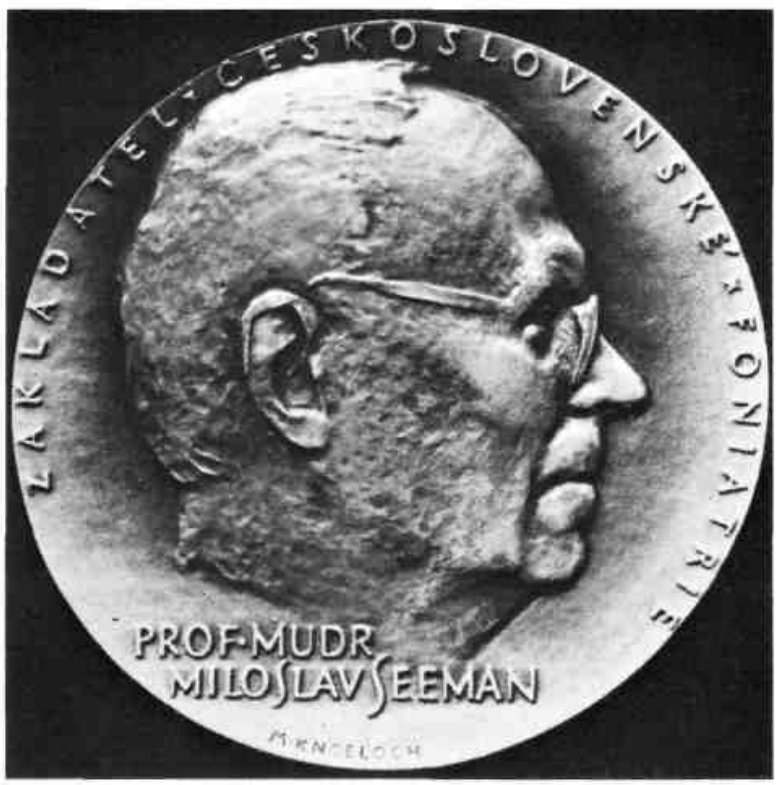

Varia

127

Der 11. Februar erinnert uns an Professor Miloslav Seeman, einen der Be-griinder und Klassiker der Phoniatrie, der uns gerade vor einem Jahr, vier Tage vor seinem 83. Geburtstag, verlassen hat.

Die Bedeutung Professor Seemans und sein Lebenswerk erwähnten wir in „Folia Phoniatrica” (25: 1-8, 1973) bei der Gelegenheit seines 80. Lebensjubi-läums, das er bei voller Gesundheit und in Freude über sein Werk im Kreise seiner Familienmitglieder und seiner Schüler feierte. Einige Wochen danach wurde er mit einem - dem für ihn schwersten - Schicksalsschlag getroffen: seine Gemahlin, sein treuester Lebensgefährte und die Stütze seines ganzen Lebens, hat ihn unerwartet für immer verlassen. Erst dann begann Professor Seeman alle Schwierigkeiten seines langjährigen Augenleidens zu fúhlen, welche ihm seine Gattin alle Jahre hindurch so leicht zu überwinden half. Er konnte sich der Arbeit an der Klinik und im Forschungslaboratorium nicht mehr so widmen wie früher und konnte an den Sitzungen des 
Kongresses der Union der Europäischen Phoniater im Jahre 1973, obwohl dieser in Prag stattfand, leider nicht regel-mässig teilnehmen.

Professor Seeman war einer der letzten Klassiker der Phoniatrie und Schüler der H.-GutzmannSchule. Prof. Gutzmanns Persönlichkeit imponierte Seeman sehr; vor allem deshalb, weil Gutzmann seine Arbeit immer nur auf der Basis wissenschaftlicher Resultate aufbaute und alle seine Schlussfolgerungen nur auf-grund objektiv festgelegter Tatsachen zog. Seeman war kein Freund komplizier-ter Spekulationen ohne objektive Grundlagen, welche er als ,philosophisch” bezeichnete, die aber in einigen damaligen Schulen stark gepflegt wurden. Er schreibt darüber auch in seinem Artikel: „Über die Entwicklung der Phoniatrie” in der tschechoslowakischen Zeitschrift „Ceskoslovenská otolaryngologie” (VI-5: 257-265, 1957).

Obwohl er Gutzmann sehr schätzte, bestand er jedoch keineswegs auf dessen Methoden und Ideen. Im Gegenteil, er entwickelte neue, moderne Arbeitsmethoden und wählte deshalb Schüler mit verschiedenen Arbeitsrichtungen. Besonders unterstützte er in seiner Arbeit die damals moderne wissenschaftliche Forschung sowohl in der Akustik als auch in der Beeinflussung des vegetativen Nervensystems sowie physiologische und phonetische Arbeitsmethoden. Er wusste aus den erreichten Resultaten eine Reihe von Theorien abzuleiten. Die Arbeit seiner Schule konnte sich besonders dann entwickeln, als es ihm gelungen war, eine selbständige Forschungsstelle aufzubauen, die aus einer selbständigen phoniatrischen Universitätsklinik und einem phoniatrischen wissenschaftlichen Laboratorium besteht.

Professor Seeman war vom Anfang seiner Tätigkeit an eine der leitenden Persönlichkeiten der Phoniatrie, hat sich sehr aktiv an der Arbeit der IALP beteiligt und organisierte in Prag im Jahre 1930 den Kongress der IALP. Er ist auch einer der Gründungsredakteure der „Folia Phoniatrica”. Professor Seeman ist Begründer der tschechoslowakischen Phoniatrie; er hat

Varia

128

ihr eine wissenschaftliche Grundlage gegeben; er hat eine Forschungs- und Studienbasis aufgebaut, die zur Entstehung einer grossen Schule führte; er hat mit seinen Mitarbeitern einen phoniatrischen Dienst im Lande organisiert, der als Muster auch für andere Lander diente. Seine 120 wissenschaftlichen Arbeiten sind alle für die Phoniatrie von grundlegender Bedeutung. Seemans Monographie „Sprachstörungen bei Kindern” wurde in vier Weltsprachen übersetzt und ist eines der Handbücher der Rehabilitation der Sprache und des Gehörs. Alle seine Werke sowie seine ganze Arbeit verweisen auf seine einheitliche Konzeption der Phoniatrie, die alle Funktionen des Kommunikationsprozesses - d.h. die Stimme, die Sprache und das Gehör einschliesst, welche als untrennbar und gleichzeitig im Einklang wechselseitiger Beziehungen angesehen werden müssen. Diese Konzeption, die uns heutzutage ganz natürlich scheint, so dass sie auch von der Union der Europäischen Phoniater akzeptiert wurde, wurde gerade vor 50 Jahren von Seeman ins Leben gerufen.

Professor Seeman war ein hervorragender Pädagoge, der seine Vorlesungen immer mit grosser Freude vorgetragen hat, und es war ein Vergnügen, ihm zuzu-hören. Er wusste immer einen Kreis junger Menschen an sich zu fesseln und für eine intensive fachmännische und wissenschaftliche Arbeit zu begeistern. So hat er seine grosse Schule geschaffen, die sich nicht nur auf das Territorium der CSSR begrenzt, sondern zu der auch viele ausländische Phoniater gehören. Seeman war alien seinen Mitarbeitern und Schülern ein Freund und Ratgeber. Um ihn herum herrschte immer eine Atmosphäre voller Vertrauen und Freund-schaft.

In den letzten Jahren litt Professor Seeman an einer Herzkrankheit, die sich gut kompensierte. Während seines ganzen Lebens verstand er mit bewunderns-werter Ausgeglichenheit alle 
Schwierigkeiten zu überwinden, die aus seinem Augenleiden entsprangen. Die Tatsache, dass er mit diesem Sehfehler sein ganzes Lebenswerk vollbrachte, welches ihn unter die Nestoren der Phoniatrie einreiht, ist der Beweis seiner ungeheuren Energie und heroischen Willenskraft, mit denen er alle Hindernisse zu überwinden wusste. Die tschechoslowakische Phoniatrie sowie die Phoniatrie der ganzen Welt hat mit dem Ableben Professor Seemans eine hervorragende

Persönlichkeit verloren, deren Werk und Lebensschicksal bestimmt noch in späterer Zeit vollste Bewunderung und Anerkennung fínden werden.

Eva Sedlácková 